\title{
NODULAÇÃO E RENDIMENTO DE SOJA CO-INFECTADA COM BACILLUS SUBTILIS E BRADYRHIZOBIUM JAPONICUM I BRADYRHIZOBIUM ELKANII ${ }^{1}$
}

\author{
FÁBIO FERNANDO DE ARAÚJO² e MARIANGELA HUNGRIA ${ }^{3}$
}

\begin{abstract}
RESUMO - O Bacillus subtilis pode favorecer o desempenho simbiótico do rizóbio, pelos efeitos na inibição de fitopatógenos ou pela exsudação de fitormônios. Com o objetivo de verificar a viabilidade da co-infecção de sementes de soja com Bradyrhizobium e Bacillus foram conduzidos três experimentos, no Paraná, em solos com população estabelecida de Bradyrhizobium, em que as estirpes de Bradyrhizobium SEMIA 5019 e SEMIA 5080 e suas variantes tolerantes aos metabólitos de Bacillus foram co-infectadas com duas estirpes de Bacillus (AP-3 e PRBS-1), ou seus metabólitos. Na safra 1993/94, em Londrina, o tratamento de co-inoculação de Bradyrhizobium com os metabólitos formulados de Bacillus incrementou, significativamente, em relação ao não-inoculado, o número de nódulos (59\%, estádio V3), a ocupação dos nódulos pelas estirpes de Bradyrhizobium (76\%, R2) e o rendimento de grãos (24\%); em Ponta Grossa, esses incrementos foram de $60 \%, 145 \%$ e $22 \%$, respectivamente. Nessa safra, em Londrina, a co-inoculação das variantes tolerantes com os metabólitos de Bacillus também aumentou o rendimento (26\%) e N total (17\%) dos grãos de soja e incrementos significativos foram constatados, na ocupação dos nódulos, pela co-inoculação das variantes tolerantes com as células de Bacillus (78\%). Os resultados obtidos indicam a viabilidade da co-inoculação, em sementes de soja, de metabólitos brutos ou formulados ou, ainda, de células de Bacillus subtilis, para incrementar a contribuição do processo de fixação biológica do nitrogênio.
\end{abstract}

Termos para indexação: controle biológico, fixação biológica do nitrogênio, Glycine max, inoculação, inoculante.

\author{
SOYBEAN NODULATION AND YIELD WHEN CO-INOCULATED \\ WITH BACILLUS SUBTILIS AND BRADYRHIZOBIUM JAPONICUM /BRADYRHIZOBIUM ELKANII
}

\begin{abstract}
Bacillus subtilis can improve rhizobial symbiotic performance by inhibiting plant pathogens or by the exudation of hormones. To verify the viability of co-inoculation of soybean seeds with Bradyrhizobium and Bacillus, three experiments were performed, in the State of Paraná, Brazil, in soils with established population of Bradyrhizobium. The Bradyrhizobium strains SEMIA 5019 and SEMIA 5080, and their natural variant strains tolerant to the metabolites of Bacillus were co-inoculated with two strains of Bacillus (AP-3 and PRBS-1), or their metabolites. In 1993/94, in Londrina, the coinoculation of Bradyrhizobium with formulated metabolites increased significantly, in relation to noninoculated control, nodule number (59\%, stage V3), nodule occupancy by Bradyrhizobium strains carried on the inoculant $(76 \%, \mathrm{R} 2)$ and soybean yield (24\%); in Ponta Grossa, these increases were of $60 \%, 145 \%$ and $22 \%$, respectively. Also in Londrina, the co-inoculation of the variant strains with crude metabolites of Bacillus has also increased yield (26\%) and total $\mathrm{N}$ in grains (17\%) and increases were verified by the co-inoculation of the Bradyrhizobium variant strains with Bacillus cells (78\%). Consequently, the results have shown the viability of co-inoculating soybean seeds with crude or formulated metabolites, or with cells of Bacillus subtilis, to increase the contribution of the biological nitrogen fixation process.
\end{abstract}

Index terms: biological control, biological nitrogen fixation, Glycine max, inoculation, inoculant.

\footnotetext{
${ }^{1}$ Aceito para publicação em 6 de outubro de 1998.

Financiado pela FINEP/CNPq/MICT, PRONEX, 41.96.0884.00.

${ }^{2}$ Eng. Agr., M.Sc., Embrapa-Centro Nacional de Pesquisa de Soja (CNPSo), Caixa Postal 231, CEP 86001-970 Londrina, PR. Bolsista da Capes.

${ }^{3}$ Eng $^{\text {a }}$ Agr ${ }^{\text {a }}$, Ph.D., Embrapa-CNPSo. Bolsista do CNPq.

E-mail: hungria@cnpso.embrapa.br
}

\section{INTRODUÇÃO}

Na cultura da soja, como na maioria das espécies cultivadas, o fornecimento de fertilizantes nitrogenados apresenta baixa eficiência de utilização por parte da planta, devido às perdas elevadas que ocorrem, particularmente por lixiviação e 
volatilização. $\mathrm{O}$ nitrogênio $(\mathrm{N})$, necessário para o desenvolvimento da soja, que exporta cerca de $150 \mathrm{~kg} \mathrm{ha}^{-1}$ de $\mathrm{N}$ nos grãos, poderá ser fornecido eficientemente através da simbiose com bactérias do gênero Bradyrhizobium (Hungria et al., 1994). Taxonomicamente, as bactérias que nodulam a soja foram classificadas, inicialmente, na espécie Rhizobium japonicum (Fred et al., 1932), posteriormente reclassificada como Bradyrhizobium japonicum (Jordan, 1982) e, recentemente, subdividida em B.japonicum e B. elkanii (Kuykendall et al., 1992). Contudo, existe grande variabilidade, entre as estirpes que nodulam a soja, quanto à eficiência do processo simbiótico e à capacidade competitiva frentes às bactérias estabelecidas no solo.

Triplett (1990) citou que a introdução de estirpes de rizóbio, superiores na fixação de $\mathrm{N}_{2}$, geralmente não é bem-sucedida, dada a sua inabilidade em ocupar os nódulos em solos com população elevada de estirpes nativas (indígenas) ou naturalizadas (introduzidas e estabelecidas). A competitividade de uma estirpe de rizóbio é influenciada por diversos fatores, relacionados com os genótipos das bactérias, da planta hospedeira e fatores ambientais (Triplett, 1990; Bottomley, 1992; Mytton \& Skøt, 1993; Hungria et al., 1994; Streeter, 1994).

A ocupação dos nódulos por estirpes de rizóbio introduzidas no solo, via inoculantes, tornou-se um desafio para os rizobiologistas, que vêm desenvolvendo diversos trabalhos, em diferentes áreas da pesquisa, para solucioná-lo. Além das pesquisas conduzidas estritamente com o rizóbio para aumentar sua competitividade intrínseca, outros estudos avaliam o efeito da interação entre o rizóbio e outros microrganismos. Nesse contexto, Li \& Alexander (1988) conseguiram incrementar a colonização e a nodulação de soja, através da co-inoculação de B. japonicum com bactérias do gênero Bacillus, produtoras de antibióticos. Inicialmente, foram obtidas variantes de $B$. japonicum eficientes e tolerantes aos antibióticos de Bacillus spp. A seguir, a variante resistente a antibióticos ocupou mais nódulos quando co-infectada com Bacillus em um solo com população de Bradyrhizobium estabelecida (Li\&Alexander, 1988).

Pesq. agropec. bras., Brasília, v.34, n.9, p.1633-1643, set. 1999
Outros relatos demonstram efeitos positivos na nodulação pela co-inoculação de rizóbio com outras espécies de bactérias. Essa contribuição foi relacionada com a produção de fitormônios, pectinase ou sinais moleculares, em Bacillus cereus (Halverson \& Handelsman, 1991), Azospirillum spp. (Singh \& Rao, 1979; Plazinski \& Rolfe, 1985; Andreeva et al., 1991), Agrobacterium (Caetano-Anollés \& Bauer, 1988) e outras espécies de microrganismos (Omar \& Abd-Alla, 1994).

Diante desses resultados, em diversos laboratórios tem-se procurado isolar e identificar microrganismos, ou componentes presentes em seus metabólitos, que possam influenciar a eficiência de fixação do $\mathrm{N}_{2}$ e a capacidade competitiva do rizóbio. No Brasil, porém, estudos sobre a co-inoculação de bradirrizóbio e bacilos na cultura da soja ainda não foram conduzidos.

Este trabalho buscou, portanto, estudar a viabilidade da co-inoculação de Bradyrhizobium japonicum/Bradyrhizobium elkanii com Bacillus subtilis em soja, como uma alternativa viável para incrementar a competitividade das estirpes de rizóbio e a eficiência da simbiose com a soja.

\section{MATERIAL E MÉTODOS}

\section{Bactérias e plantas}

As estirpes de Bradyrhizobium utilizadas foram B. elkanii SEMIA $5019(=29 \mathrm{w},=\mathrm{BR} 29)$ e $B$. japonicum SEMIA 5080 (=CPAC 7). As estirpes de Bacillus subtilis utilizadas foram a AP-3, de comprovado efeito antagônico a fungos fitopatogênicos (Bettiol \& Kimati, 1990) (cedida pelo Dr. Wagner Bettiol, Embrapa-Centro Nacional de Pesquisa de Monitoramento e Avaliação de Impacto Ambiental (CNPMA), Jaguariúna, SP) e a estirpe PRBS1, isolada de solo sob cultivo com soja, no campo experimental da Embrapa-Centro Nacional de Pesquisa de Soja (CNPSo) (Araújo et al., 1995).

Foram utilizadas as cultivares de soja [Glycine max (L.) Merrill] BR-16 e BR-37 e, como cultura de inverno, a cultivar BR-23 de trigo (Triticum aestivum L). As sementes foram fornecidas pelo banco de germoplasma da EmbrapaCNPSo. 
Obtenção de variantes de Bradyrhizobium tolerantes aos metabólitos de Bacillus

As estirpes de Bradyrhizobium SEMIA 5019 e SEMIA 5080 foram submetidas a testes de tolerância aos metabólitos de B. subtilis AP-3, seguindo metodologia de Li \& Alexander (1988). O B. subtilis foi multiplicado por sete dias, a $28^{\circ} \mathrm{C}$, em meio líquido batata-dextrose $(\mathrm{BD}$, contendo $250 \mathrm{~g} \mathrm{~L}^{-1}$ de batata, $10 \mathrm{~g} \mathrm{~L}^{-1}$ de dextrose, $\mathrm{pH} 6,5$ ), sob agitação de $100 \mathrm{rpm}$. As células foram separadas por centrifugação $(10.000 \mathrm{~g}, 10$ minutos) e o sobrenadante foi adicionado ao meio com extrato de levedura-manitol YMC (Somasegaran \& Hoben, 1994), acondicionado em frascos erlenmeyer de $250 \mathrm{~mL}$, contendo $100 \mathrm{~mL}$ da mistura, nas proporções de 1/3,1/1 e de 9/1 (sobrenadante de Bacillus/meio YM). As estirpes de Bradyrhizobium foram inoculadas, primeiramente, nos frascos com a proporção 1/3 (sobrenadante/meio de cultura), sendo as culturas incubadas a $28^{\circ} \mathrm{C}$, sob agitação de $100 \mathrm{rpm}$. Quando o crescimento foi evidente, as culturas foram plaqueadas em meio extrato de YMA (com ágar) na proporção $1 / 3$ (sobrenadante/meio). As colônias formadas foram isoladas e inoculadas em meio líquido YM contendo a proporção $1 / 1$ dos dois componentes e, a seguir, o procedimento foi repetido para a proporção $9 / 1$. As colônias formadas no meio sólido com a proporção $9 / 1$ foram isoladas e caracterizadas como tolerantes aos metabólitos do B. subtilis (AP-3), sendo mantidas em tubos com meio sólido (YM), contendo sobrenadante na proporção 9/1. Os estudos, a partir deste teste, foram conduzidos, também, com as variantes tolerantes, as quais foram denominadas de B. japonicum SEMIA 5080-T e B. elkanii SEMIA 5019-T.

Ensaios, a campo, com co-inoculação de Bacillus e Bradyrhizobium

Foram conduzidos três experimentos de campo. $\mathrm{Na}$ safra 93/94, foram implantados dois experimentos, um no campo experimental da Embrapa-CNPSo, em Londrina, distrito da Warta, em um Latossolo Roxo distrófico e outro na Embrapa-Serviço de Produção de Sementes Básicas, em Ponta Grossa, em um Latossolo Vermelho-Escuro álico. Na safra 94/95, o experimento foi repetido na mesma área de Londrina, com os mesmos tratamentos reinfectados nas mesmas parcelas. As propriedades químicas dos solos, na camada de $0-20 \mathrm{~cm}$, podem ser vistas na Tabela 1 . $\mathrm{Na}$ área do experimento de Ponta Grossa foram incorporadas, ao solo, $5 \mathrm{t} \mathrm{ha}^{-1}$ de calcário dolomítico, um ano antes da semeadura. A parcela experimental, nos três experimentos, teve dimensões de 3,0 $\mathrm{m}$ x 2,0 $\mathrm{m}$, com linhas de soja distanciadas por $0,5 \mathrm{~m}$. As parcelas foram separadas, uma das outras, por caminhos de $2,0 \mathrm{~m}$ e por pequenos terraços, para evitar contaminação entre os tratamentos. Na safra 93/94 foi realizada, em Londrina, uma adubação cinco dias antes da semeadura, a lanço, com incorporação de $250 \mathrm{~kg}$ de superfosfato simples e $35 \mathrm{~kg}$ de cloreto de potássio. Em Ponta Grossa, foram adicionados $500 \mathrm{~kg}$ de superfosfato simples, $35 \mathrm{~kg}$ de cloreto de potássio e $30 \mathrm{~kg}$ de micronutrientes (FTE-BR-12, óxido silicatado contendo, em \%: Zn, 9,0; B, 1,80; Cu, 0,8; Fe, 3,0; Mn, 2,0; Mo, 0,10). No experimento realizado em Londrina, na mesma área, no ano seguinte, foi realizada a adubação com $300 \mathrm{~kg} \mathrm{ha}^{-1}$ de N-P-K (0-20-20).

A população de rizóbio do solo foi determinada pela técnica do número mais provável em plantas (NMP), utilizando-se a cultivar de soja BR-16, conforme descrito em Andrade \& Hamakawa (1994). Em Londrina, o solo apresentou uma população estabelecida de $3,6.10^{4} \mathrm{e}$ $5,0.10^{4}$ células $\mathrm{g}^{-1}$ de solo, no primeiro e no segundo ano, respectivamente. Em Ponta Grossa, a população foi de $6,0.10^{5}$ células $\mathrm{g}^{-1}$ de solo. Na safra 93/94, a população de Bacillus foi estimada pela contagem das colônias formadas em placas, após choque térmico de $70^{\circ} \mathrm{C}$, por 10 minutos (Buchanan \& Gibbons, 1975), em 3,0.104 e 3,5.105 células $\mathrm{g}^{-1}$ de solo, respectivamente em Londrina e Ponta Grossa. Na safra seguinte, em Londrina, a população de Bacillus foi, em média, de $1,5.10^{4}$ células $^{-1}$ de solo.

Os experimentos foram conduzidos com as cultivares de soja BR-16 (safra 93/94) e BR-37 (safra 94/95), em Londrina e BR-37, na safra 93/94, em Ponta Grossa. Foram utilizadas, aproximadamente, 30 sementes $\mathrm{m}^{-1}$ e os seguintes tratamentos: 1- inoculação de estirpes de Bradyrhizobium SEMIA 5019 + SEMIA 5080. Estirpes crescidas em YM e padronizadas a $5,0.10^{7}$ células semente ${ }^{-1} ; 2$ - inoculação das variantes de Bradyrhizobium tolerantes aos metabólitos

TABELA 1. Propriedades químicas dos solos.

\begin{tabular}{llllllrrc}
\hline Local & $\begin{array}{l}\mathrm{pH} \mathrm{em} \\
\mathrm{CaCl}_{2}\end{array}$ & $\mathrm{Al}$ & $\mathrm{K}$ & $\begin{array}{c}\mathrm{Ca} \\
-------------- \\
\left(\mathrm{cmol}_{\mathrm{kg}^{-1}}\right)\end{array}$ & $\mathrm{Mg}$ & $\mathrm{H}+\mathrm{Al}$ & $\begin{array}{c}\mathrm{C} \\
\left(\mathrm{g} \mathrm{kg}^{-1}\right)\end{array}$ & $\begin{array}{c}\mathrm{P} \\
\left(\mathrm{mg} \mathrm{kg}^{-1}\right)\end{array}$ \\
\hline Londrina (93/94) & 4,60 & 0,05 & 0,47 & 2,14 & 1,71 & 5,71 & 1,77 & 9,6 \\
Ponta Grossa & 4,23 & 0,60 & 0,13 & 0,59 & 1,95 & 10,21 & 2,63 & 1,4 \\
Londrina (94/95) & 4,89 & 0,07 & 0,56 & 4,68 & 1,69 & 3,08 & 1,12 & 9,4 \\
\hline
\end{tabular}


de Bacillus (5019-T e 5080-T), também na concentração de $5,0.10^{7}$ células semente ${ }^{-1} ; 3$ - co-inoculação de Bradyrhizobium $(5019+5080)$ e células e Bacillus spp. (AP-3 + PRBS-1). As estirpes de Bacillus foram crescidas em meio BD por sete dias, a $28^{\circ} \mathrm{C}$ e agitação a $100 \mathrm{rpm}$. As culturas foram, então, centrifugadas a $20.000 \mathrm{~g}$ por 20 minutos, obtendo-se a fração de metabólitos brutos e células. As células foram lavadas por duas vezes com solução salina $(\mathrm{NaCl}, 0,85 \%)$ e padronizadas em $1.10^{6}$ células semente $^{-1}$; 4- co-inoculação das estirpes tolerantes de Bradyrhizobium (5019-T e 5080-T) e das células de Bacillus, conforme descrito no tratamento 3; 5- coinoculação de Bradyrhizobium (5019 + 5080) com os metabólitos brutos de Bacillus. Os metabólitos brutos foram obtidos conforme descrito no tratamento 3 e utilizados na concentração de $40 \mathrm{~mL} 500 \mathrm{~g}^{-1}$ de sementes; 6- co-inoculação das variantes tolerantes de Bradyrhizobium (5019-T + 5080-T) com os metabólitos brutos de Bacillus, conforme descrito no tratamento 5; 7- metabólitos formulados de B. subtilis (AP-3) na forma de pó-molhável (formulação técnica desenvolvida pela Embrapa-CNPMA). Para a obtenção do formulado, os metabólitos brutos, obtidos conforme descrito no tratamento 3 , foram solubilizados em metanol e, a seguir, centrifugados a $20.000 \mathrm{~g}$ por 15 minutos, a $4^{\circ} \mathrm{C}$. O sobrenadante foi descartado, e o precipitado contendo os antibióticos foi utilizado como ingrediente ativo na formulação do pó molhável. A formulação, contendo $5 \%$ dos metabólitos, foi utilizada na concentração de $0,15 \mathrm{~g}$ do princípio ativo $500 \mathrm{~g}^{-1}$ de sementes; 8- extrato de antibióticos de B. subtilis (AP-3), utilizado na concentração de $0,1 \mathrm{~g}$ de extrato $500 \mathrm{~g}^{-1}$ de sementes. O precipitado contendo antibióticos foi obtido conforme descrito no tratamento 7 e solubilizado em metanol e centrifugado a $20.000 \mathrm{~g}$ por 10 minutos. A seguir, coletou-se o sobrenadante contendo os antibióticos brutos solubilizados, sendo determinada a concentração aproximada dos mesmos através da relação peso:volume, em comparação com o mesmo volume de metanol puro. Desse modo, encontrou-se uma concentração de $0,5 \mathrm{~g}$ de antibióticos $100 \mathrm{~mL}^{-1}$ de metanol. Essa metodologia fundamentou-se na descrita por McKeen et al. (1986); 9- tratamento não-inoculado.

A primeira coleta foi realizada no estádio vegetativo V3 de desenvolvimento e dez plantas de cada parcela foram coletadas, determinando-se o número e a massa de nódulos secos. Foi avaliada, também, a população de Bacillus spp. na rizosfera de soja. Para isso, coletaram-se dez plantas por parcela, cujas raízes foram separadas e, posteriormente, agitadas levemente para descartar o solo não aderido. No laboratório, as raízes foram agitadas vigorosamente durante um minuto dentro de um saco de plástico e o solo remanescente no fundo do saco foi homogeneizado, por agitação manual, extraindo-se, a seguir, $1 \mathrm{~g}$ desse solo que estava aderido às raízes. A contagem de Bacillus spp. no material foi realizada pelo método de diluição em placa, precedido de choque térmico, conforme já relatado. A segunda coleta foi realizada no estádio R2, avaliando-se o número e a massa de nódulos secos de dez plantas. Além disso, 40 nódulos por parcela foram caracterizados sorologicamente, pela técnica de aglutinação direta em placas de poliestireno em "U" (Somasegaran \& Hoben, 1994) contra os anti-soros das estirpes SEMIA 5019 e SEMIA 5080. A parte aérea foi separada da raiz, e ambas, colocadas para secagem a $65^{\circ} \mathrm{C}$, até atingirem massa constante. A parte aérea foi moída avaliando-se, então, o teor de $\mathrm{N}$ total pelo método de Feije \& Anger (1972). Na coleta final, foi determinado o rendimento dos grãos, após correção para $13 \%$ de umidade e o teor de $\mathrm{N}$ total dos grãos. Após a cultura da soja, nos três ensaios, foi semeado trigo nas mesmas parcelas, sem receber nenhuma adubação ou correção de solo. Na coleta final, foi determinado o rendimento de grãos de trigo, corrigido para $13 \%$ de umidade. Os experimentos foram conduzidos em blocos ao acaso, com seis repetições. Os dados foram submetidos à análise de variância e as médias foram comparadas pelo teste de Tukey, a 5\% de probabilidade.

\section{RESULTADOS E DISCUSSÃO}

Em Londrina, na safra 93/94, foi constatado, na coleta realizada no estádio V3, que a co-inoculação de Bradyrhizobium com metabólitos formulados de Bacillus aumentou significativamente o número de nódulos, em 59\%, em relação ao tratamento não-inoculado, e em $27 \%$ (não-significativo estatisticamente) em relação à inoculação exclusivamente de Bradyrhizobium, resultando, ainda, em maior massa nodular (Tabela 2). Provavelmente pela população naturalizada elevada de rizóbio no solo, o número e a massa de nódulos não tenham sido, nos demais tratamentos inoculados com Bradyrhizobium, significativamente superiores ao controle sem inoculação. Na coleta realizada no estádio R2, não foram constatadas diferenças estatísticas, entre os diversos tratamentos, nos parâmetros de nodulação. O tratamento co-inoculado com metabólitos e estirpes de Bradyrhizobium tolerantes, porém, apresentou boa nodulação, resultando em maior acúmulo de $\mathrm{N}$ total na parte aérea, superior em $116 \%$ em relação à testemunha não-inoculada e em $120 \%$ em relação à inoculação exclusivamente com as estirpes tolerantes (Tabela 2). 
TABELA 2. Nodulação (estádios V3 e R2), massa e N total acumulado na parte aérea (R2) de soja, cultivar BR-16, infectada com duas estirpes de Bradyrhizobium (SEMIA 5019 + SEMIA 5080) ou suas variantes naturais tolerantes aos metabólitos de Bacillus e co-infectada com duas estirpes de Bacillus (AP-3 + PRBS-1), ou seus metabólitos. Experimento conduzido em Londrina, na safra 93/94, em um Latossolo Roxo distrófico com população estabelecida de $3,6.10^{4}$ células de Bradyrhizobium e 3,0.104 células de Bacillus por g de solo. Médias de seis repetições ${ }^{1}$.

\begin{tabular}{|c|c|c|c|c|c|c|}
\hline \multirow[t]{2}{*}{ Tratamento } & \multicolumn{2}{|c|}{ Nodulação (V3) } & \multicolumn{2}{|c|}{ Nodulação (R2) } & \multicolumn{2}{|c|}{ Parte aérea (R2) } \\
\hline & $\left(\mathrm{n}^{\mathrm{o}} \mathrm{pl}^{-1}\right)$ & $\left(\mathrm{mg} \mathrm{pl} \mathrm{l}^{-1}\right)$ & $\left(\mathrm{n}^{\mathrm{o}} \mathrm{pl}^{-1}\right)$ & $\left(\mathrm{mg} \mathrm{pl}^{-1}\right)$ & $\begin{array}{c}\text { Massa } \\
\left(\mathrm{g} \mathrm{pl}^{-1}\right)\end{array}$ & $\begin{array}{l}\mathrm{N} \text { total } \\
\left(\mathrm{mg} \mathrm{pl}^{-1}\right)\end{array}$ \\
\hline Bradyrhizobium & $14,8 \mathrm{ab}$ & $40,9 \mathrm{ab}$ & $30,8 \mathrm{a}$ & $129,6 \mathrm{a}$ & $7,03 b c$ & $248,4 b c$ \\
\hline $\operatorname{Bradyrhizobium}(\mathrm{T})^{2}$ & $14,3 \mathrm{ab}$ & $41,0 \mathrm{ab}$ & $34,3 \mathrm{a}$ & $134,3 \mathrm{a}$ & $6,21 b c$ & $163,9 \mathrm{c}$ \\
\hline Brady. + Bacillus $^{3}$ & $14,1 \mathrm{ab}$ & $38,6 \mathrm{ab}$ & $33,4 \mathrm{a}$ & $140,5 \mathrm{a}$ & $7,28 b c$ & $172,3 \mathrm{c}$ \\
\hline Brady. $(\mathrm{T})+$ Bacillus & $14,6 a b$ & $35,6 b$ & $35,0 \mathrm{a}$ & $147,5 \mathrm{a}$ & $7,09 \mathrm{bc}$ & $170,2 \mathrm{c}$ \\
\hline Brady.+metabólitos ${ }^{4}$ & $14,7 \mathrm{ab}$ & $37,9 \mathrm{ab}$ & $30,2 \mathrm{a}$ & $138,9 \mathrm{a}$ & $7,80 \mathrm{~b}$ & $265,6 b$ \\
\hline Brady.(T)+metabólitos & $17,8 \mathrm{ab}$ & $49,2 \mathrm{ab}$ & $41,7 \mathrm{a}$ & $159,5 \mathrm{a}$ & $10,60 \mathrm{a}$ & $360,7 \mathrm{a}$ \\
\hline Brady.+formulação ${ }^{5}$ & $18,8 \mathrm{a}$ & $56,6 \mathrm{a}$ & $38,9 a$ & $144,3 \mathrm{a}$ & $6,57 \mathrm{bc}$ & $241,1 b c$ \\
\hline Brady.+ext. alcoólico ${ }^{6}$ & $15,6 a b$ & $42,6 a b$ & $40,1 \mathrm{a}$ & $164,7 \mathrm{a}$ & $7,46 b c$ & $229,9 \mathrm{bc}$ \\
\hline Não-inoculado & $11,8 \mathrm{~b}$ & $40,1 \mathrm{ab}$ & $29,8 \mathrm{a}$ & $132,8 \mathrm{a}$ & $4,90 \mathrm{c}$ & $166,6 \mathrm{c}$ \\
\hline CV (\%) & 20,3 & 24,8 & 21,8 & 22,7 & 28,2 & 29,1 \\
\hline
\end{tabular}

${ }^{1}$ Médias seguidas de mesma letra não diferem, estatisticamente, pelo teste de Tukey $(\mathrm{P}<0,05)$.

${ }^{2}$ Bradyrhizobium tolerante (T) aos metabólitos de Bacillus.

${ }^{3}$ Bradyrhizobium adicionado na concentração de 5,0.10 células semente $^{-1}$ e Bacillus na concentração de $1,0.10^{6}$ células semente ${ }^{-1}$.

${ }^{4}$ Metabólitos adicionados na concentração de $40 \mathrm{~mL}$ de metabólitos $500 \mathrm{~g}^{-1}$ de sementes.

${ }^{5}$ Metabólitos do Bacillus extraídos segundo McKeen et al. (1986), formulados como pó-molhável (5\% dos metabólitos), misturados às sementes na proporção de $0,15 \mathrm{~g}$ do princípio ativo para $500 \mathrm{~g}$ de sementes.

${ }^{6}$ Extrato alcoólico contendo $0,5 \%$ de metabólitos purificados do Bacillus, obtidos segundo McKeen et al. (1986), misturado às sementes na proporção de $0,1 \mathrm{~g}$ do extrato para $500 \mathrm{~g}$ de sementes.

Em Ponta Grossa, na safra 93/94, observou-se, de um modo geral, tanto na primeira (V3) como na segunda (R2) coleta, um aumento na nodulação em todos os tratamentos infectados com Bradyrhizobium (Tabela 3). Esse estímulo no número de nódulos foi estatisticamente superior quando o bradirrizóbio foi co-inoculado com a formulação (60\% em V3 e 72\% em R2) ou, ainda, com bradirrizóbio tolerante, na presença de metabólitos de Bacillus ( $60 \%$ em V3), em relação ao controle não-infectado. Houve incremento, mas não estatisticamente significativo, em relação à inoculação somente de Bradyrhizobium. Não foram constatadas diferenças entre os tratamentos e a população naturalizada na massa e $\mathrm{N}$ total da parte aérea em R2 (Tabela 3).

Na safra 93/94, em Londrina, a co-inoculação de variantes de Bradyrhizobium tolerantes com células de Bacillus, ou de Bradyrhizobium com os formulados, incrementou a ocupação total de nódulos, em relação ao tratamento não-infectado, respectivamente, em $78 \%$ e $76 \%$; também foram significativos os incrementos em relação à inoculação exclusiva de Bradyrhizobium ( $88 \%$ e $85 \%$, respectivamente) (Tabela 4). Em Ponta Grossa, todos os tratamentos, exceto a variante tolerante, conseguiram incrementar a ocupação dos nódulos em relação à população naturalizada do solo, chegando a um máximo de $200 \%$ $\operatorname{(Bradyrhizobium}(\mathrm{T})+$ metabólitos). Esse tratamento também superou em $25 \%$, mas não estatisticamente, o infectado exclusivamente com Bradyrhizobium (Tabela 4). Em ambos os locais, os incrementos na porcentagem de ocupação dos nódulos estiveram relacionados com a maior participação das duas estirpes inoculadas, SEMIA 5019 e SEMIA 5080.

Em Londrina (93/94), a inoculação de Bradyrhizobium na soja incrementou, mas não significativamente, o rendimento em relação à testemunha não-infectada.

No tratamento de co-inoculação de metabólitos de Bacillus junto com as estirpes de Bradyrhizobium tolerantes (T) ou da co-inoculação com as estirpes parentais e o formulado, os ganhos no rendimento 
TABELA3. Nodulação (estádios V3 e R2), massa e $\mathbf{N}$ total acumulado na parte aérea (R2) de soja, cultivar BR-37, infectada com duas estirpes de Bradyrhizobium (SEMIA 5019 + SEMIA 5080) ou suas variantes naturais tolerantes aos metabólitos de Bacillus e co-infectada com duas estirpes de Bacillus (AP-3 + PRBS-1), ou seus metabólitos. Experimento conduzido em Ponta Grossa, na safra 93/94, em um Latossolo Vermelho-Escuro álico, com população estabelecida de 6,0.10 células de Bradyrhizobium e 3,5.105 células de Bacillus por $\mathrm{g}$ de solo. Médias de seis repetições ${ }^{1}$.

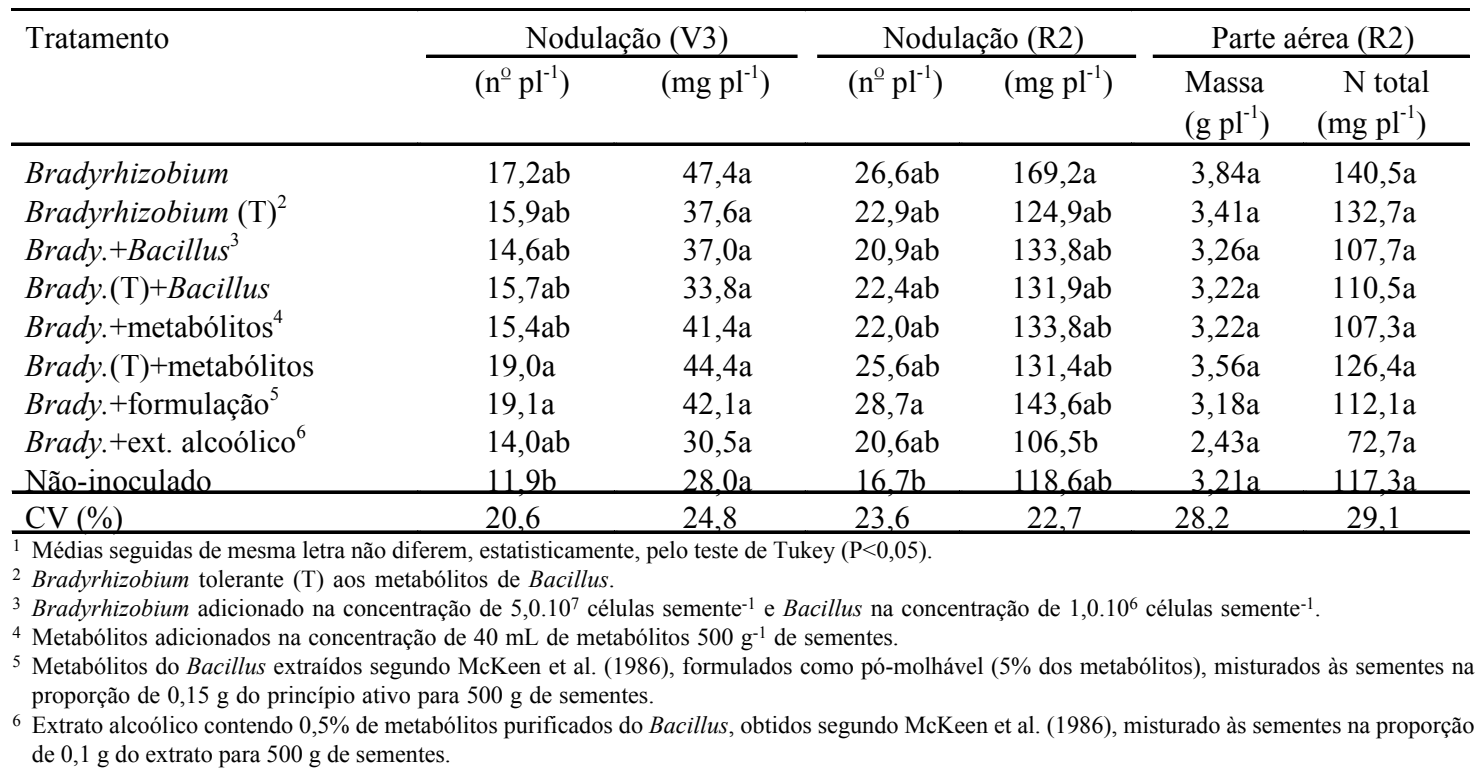

TABELA4. Efeito da co-infecção de sementes de soja com Bradyrhizobium tolerante ou não aos metabólitos de Bacillus, juntamente com a introdução de Bacillus ou seus metabólitos, na porcentagem de ocupação dos nódulos de soja (estádio R2) pelos sorogrupos das estirpes SEMIA 5019 e SEMIA 5080. Ensaios conduzidos na safra 93/94 em Londrina, em um Latossolo Roxo distrófico com população estabelecida de 3,6.10 ${ }^{4}$ células de Bradyrhizobium e, em Ponta Grossa, em um Latossolo VermelhoEscuro álico com $6,0.10^{5}$ células de Bradyrhizobium por $\mathrm{g}$ de solo. Médias de seis repetições ${ }^{1}$.

\begin{tabular}{|c|c|c|c|c|c|c|}
\hline \multirow[t]{3}{*}{ Tratamento } & \multicolumn{3}{|c|}{ Londrina } & \multicolumn{3}{|c|}{ Ponta Grossa } \\
\hline & \multicolumn{2}{|c|}{ Sorogrupo } & \multirow[t]{2}{*}{ Total } & \multicolumn{2}{|c|}{ Sorogrupo } & \multirow{2}{*}{ Total } \\
\hline & 5019 & 5080 & & 5019 & 5080 & \\
\hline Bradyrhizobium & $11,5 b$ & $8,5 \mathrm{ab}$ & $20,0 b$ & $31,0 \mathrm{a}$ & $8,5 \mathrm{~d}$ & $39,5 \mathrm{ab}$ \\
\hline $\operatorname{Bradyrhizobium}(\mathrm{T})^{2}$ & $12,5 b$ & $8,0 \mathrm{ab}$ & $20,5 b$ & $14,0 \mathrm{~cd}$ & $9,0 \mathrm{~cd}$ & $23,0 \mathrm{c}$ \\
\hline Brady.+ Bacillus $^{3}$ & $20,0 \mathrm{ab}$ & $7,0 \mathrm{ab}$ & $27,0 \mathrm{ab}$ & $34,0 \mathrm{a}$ & $10,0 \mathrm{~cd}$ & $44,0 \mathrm{a}$ \\
\hline Brady. $(\mathrm{T})+$ Bacillus & $25,5 \mathrm{a}$ & $12,0 \mathrm{a}$ & $37,5 \mathrm{a}$ & $25,0 \mathrm{ab}$ & $20,0 \mathrm{a}$ & $45,0 \mathrm{a}$ \\
\hline Brady.+metabólitos ${ }^{4}$ & $15,0 \mathrm{ab}$ & $6,0 \mathrm{~b}$ & $21,0 \mathrm{~b}$ & $31,5 \mathrm{a}$ & $10,5 \mathrm{~cd}$ & $42,0 \mathrm{a}$ \\
\hline Brady. (T)+metabólitos & $15,5 \mathrm{ab}$ & $10,0 \mathrm{ab}$ & $25,5 \mathrm{ab}$ & $32,5 \mathrm{a}$ & $17,0 \mathrm{ab}$ & $49,5 \mathrm{a}$ \\
\hline Brady.+formulação ${ }^{5}$ & $26,5 \mathrm{a}$ & $10,5 \mathrm{ab}$ & $37,0 \mathrm{a}$ & $26,0 \mathrm{ab}$ & $14,5 \mathrm{abc}$ & $40,5 \mathrm{ab}$ \\
\hline Brady.+ext. alcoólico ${ }^{6}$ & $18,5 \mathrm{ab}$ & $8,5 \mathrm{ab}$ & $27,0 \mathrm{ab}$ & $19,0 \mathrm{bc}$ & $12,0 \mathrm{bcd}$ & $31,0 \mathrm{~b}$ \\
\hline Não-inoculado & $15,0 \mathrm{ab}$ & $6,0 \mathrm{~b}$ & $21,0 \mathrm{~b}$ & $8,0 \mathrm{~d}$ & $8,5 \mathrm{~d}$ & $16,5 \mathrm{c}$ \\
\hline $\mathrm{CV}(\%)$ & 22,4 & 19.6 & 19.4 & 12.2 & 16.0 & 18.1 \\
\hline
\end{tabular}

${ }^{1}$ Médias seguidas de mesma letra não diferem, estatisticamente, pelo teste de Tukey $(\mathrm{P}<0,05)$.

2 Bradyrhizobium tolerante (T) aos metabólitos de Bacillus.

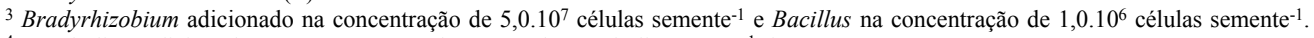

${ }^{4}$ Metabólitos adicionados na concentração de $40 \mathrm{~mL}$ de metabólitos $500 \mathrm{~g}^{-1}$ de sementes.

${ }^{5}$ Metabólitos do Bacillus extraídos segundo McKeen et al. (1986), formulados como pó-molhável (5\% dos metabólitos), misturados às sementes na proporção de $0,15 \mathrm{~g}$ do princípio ativo para $500 \mathrm{~g}$ de sementes.

${ }^{6}$ Extrato alcoólico contendo $0,5 \%$ de metabólitos purificados do Bacillus, obtidos segundo McKeen et al. (1986), misturado às sementes na proporção de $0,1 \mathrm{~g}$ do extrato para $500 \mathrm{~g}$ de sementes. 
foram estatisticamente significativos, superando a testemunha não-infectada em 522 e $498 \mathrm{~kg} \mathrm{ha}^{-1}$, respectivamente (Tabela 5). Em Ponta Grossa, observaram-se ganhos significativos no rendimento de soja, de $450 \mathrm{~kg} \mathrm{ha}^{-1}$, com a inoculação de Bradyrhizobium e metabólitos formulados de Bacillus, em relação ao tratamento sem inoculação. A co-inoculação de Bradyrhizobium com Bacillus também apresentou ganhos consideráveis no rendimento e foi o tratamento com maior teor de $\mathrm{N}$ nos grãos, acumulando $29 \mathrm{~kg} \mathrm{ha}^{-1}$ de $\mathrm{N}$ a mais do que as plantas infectadas com a população naturalizada (Tabela 5).

$\mathrm{Na}$ safra seguinte (94/95), em Londrina, onde os tratamentos foram colocados sobre as mesmas parcelas do ano anterior, não foram constatadas diferenças estatísticas no número de nódulos, no estádio R2 (Tabela 6 ). Contudo, a porcentagem de ocupação dos nódulos pelas estirpes inoculadas foi incrementada e, nos tratamentos de co-inoculação de Bradyrhizobium com células de Bacillus ou com formulado, esse estímulo foi de $326 \%$ e $344 \%$, respectivamente, em relação ao tratamento nãoinfectado (Tabela 6). A população de Bacillus, avaliada em V3, variou pouco entre os tratamentos, entre $1,6.10^{4}$ células $\mathrm{g}^{-1}$ de solo, no tratamento nãoinfectado com Bradyrhizobium ou Bacillus, a $1,25.10^{5}$ células $\mathrm{g}^{-1}$ de solo, nos tratamentos inoculados com células de Bacillus.

Na safra 94/95, ao contrário da anterior, não houve períodos de estresse hídrico, resultando em maiores rendimentos de grãos. Também não foram constatadas diferenças estatísticas entre os tratamentos no rendimento e no teor de $\mathrm{N}$ total dos grãos, embora tenham sido observados alguns destaques, como os incrementos, em relação ao tratamento nãoinfectado, obtidos pela reinoculação de bradirrizóbio e com extrato alcoólico $(285 \mathrm{~kg})$, de bradirrizóbio +

TABELA 5. Rendimento e N total nos grãos de soja, cv. BR-16 (Londrina) e BR-37 (Ponta Grossa), infectadas com duas estirpes de Bradyrhizobium (SEMIA 5019 + SEMIA 5080) e suas variantes naturais tolerantes aos metabólitos de Bacillus e co-infectadas com duas estirpes de Bacillus (AP-3 + PRBS-1), ou seus metabólitos. Experimentos conduzidos na safra 93/94 em um Latossolo Roxo distrófico de Londrina, com população estabelecida de 3,6.10 4 células de Bradyrhizobium e em um Latossolo Vermelho-Escuro álico de Ponta Grossa com 6,0.10 5 células de Bradyrhizobium por g de solo. Médias de seis repetições 1 .

\begin{tabular}{|c|c|c|c|c|}
\hline \multirow[t]{2}{*}{ Tratamento } & \multicolumn{2}{|c|}{ Londrina } & \multicolumn{2}{|c|}{ Ponta Grossa } \\
\hline & $\begin{array}{c}\text { Rendimento } \\
\left(\mathrm{kg} \mathrm{ha}^{-1}\right)\end{array}$ & $\begin{array}{l}\mathrm{N} \text { total } \\
\left(\mathrm{kg} \mathrm{ha}^{-1}\right)\end{array}$ & $\begin{array}{c}\text { Rendimento } \\
\left(\mathrm{kg} \mathrm{ha}^{-1}\right)\end{array}$ & $\begin{array}{c}\mathrm{N} \text { total } \\
\left(\mathrm{kg} \mathrm{ha}^{-1}\right)\end{array}$ \\
\hline Bradyrhizobium & $2.298 \mathrm{ab}$ & $138,3 \mathrm{bcd}$ & $2.352 \mathrm{ab}$ & $149,8 \mathrm{ab}$ \\
\hline $\operatorname{Bradyrhizobium}(\mathrm{T})^{2}$ & $2.468 \mathrm{ab}$ & $131,4 \mathrm{~cd}$ & $2.281 \mathrm{ab}$ & $146,9 \mathrm{ab}$ \\
\hline Brady. + Bacillus $^{3}$ & $2.146 \mathrm{ab}$ & $125,3 \mathrm{~d}$ & $2.409 \mathrm{ab}$ & $156,6 \mathrm{a}$ \\
\hline Brady. (T)+Bacillus & $2.183 \mathrm{ab}$ & $134,3 \mathrm{~cd}$ & $2.221 \mathrm{ab}$ & $137,0 \mathrm{ab}$ \\
\hline Brady. + metabólitos $^{4}$ & $2.366 \mathrm{ab}$ & $143,1 \mathrm{abc}$ & $2.054 \mathrm{~b}$ & $127,6 \mathrm{ab}$ \\
\hline Brady. (T)+metabólitos & $2.568 \mathrm{a}$ & $155,1 \mathrm{a}$ & $2.244 \mathrm{ab}$ & $136,2 \mathrm{ab}$ \\
\hline Brady.+formulação ${ }^{5}$ & $2.544 \mathrm{a}$ & $150,6 \mathrm{ab}$ & $2.494 \mathrm{a}$ & $147,6 \mathrm{ab}$ \\
\hline Brady.+ext. alcoólico ${ }^{6}$ & $2.484 \mathrm{ab}$ & $151,3 \mathrm{ab}$ & $1.991 \mathrm{~b}$ & $120,6 b$ \\
\hline Não-inoculado & $2.046 \mathrm{~b}$ & $132,9 \mathrm{~cd}$ & $2.044 \mathrm{~b}$ & $127,3 \mathrm{ab}$ \\
\hline $\mathrm{CV}(\%)$ & 8,0 & 5,9 & 14,6 & 15,7 \\
\hline
\end{tabular}

${ }^{1}$ Médias seguidas de mesma letra não diferem, estatisticamente, pelo teste de Tukey $(\mathrm{P}<0,05)$.

2 Bradyrhizobium tolerante (T) aos metabólitos de Bacillus.

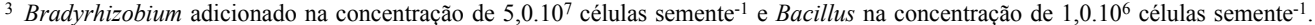

${ }^{4}$ Metabólitos adicionados na concentração de $40 \mathrm{~mL}$ de metabólitos $500 \mathrm{~g}^{-1}$ de sementes.

5 Metabólitos do Bacillus extraídos segundo McKeen et al. (1986), formulados como pó-molhável (5\% dos metabólitos), misturados às sementes na proporção de $0,15 \mathrm{~g}$ do princípio ativo para $500 \mathrm{~g}$ de sementes.

${ }^{6}$ Extrato alcoólico contendo 0,5\% de metabólitos purificados do Bacillus, obtidos segundo McKeen et al. (1986), misturado às sementes na proporção de $0,1 \mathrm{~g}$ do extrato para $500 \mathrm{~g}$ de sementes. 
TABELA 6. Número de nódulos (R2), porcentagem de ocupação desses nódulos pelas estirpes inoculadas (R2) e rendimento e $\mathbf{N}$ total dos grãos de soja, cultivar BR-37, infectada com duas estirpes de Bradyrhizobium (SEMIA 5019 + SEMIA 5080), ou suas variantes naturais tolerantes aos metabólitos de Bacillus e co-infectada com duas estirpes de Bacillus (AP-3 + PRBS-1), ou seus metabólitos. Experimento conduzido em Londrina, na safra 94/95, sob as mesmas parcelas da safra anterior, em um Latossolo Roxo distrófico com população, de 5,0.10 ${ }^{4}$ células de Bradyrhizobium e 1,5.10 ${ }^{4}$ células de Bacillus por $\mathrm{g}$ de solo. Médias de seis repetições'

\begin{tabular}{|c|c|c|c|c|c|c|}
\hline \multirow[t]{2}{*}{ Tratamento } & \multirow{2}{*}{$\begin{array}{l}\text { Nodulação } \\
\left(\mathrm{n}^{\mathrm{O}} \mathrm{pl}^{-1}\right)\end{array}$} & \multicolumn{3}{|c|}{ Ocupação dos nódulos (\%) } & \multirow{2}{*}{$\begin{array}{l}\text { Rendimento } \\
\left(\mathrm{kg} \mathrm{ha}^{-1}\right)\end{array}$} & \multirow{2}{*}{$\begin{array}{l}\mathrm{N} \text { total } \\
\left(\mathrm{kg} \mathrm{ha}^{-1}\right)\end{array}$} \\
\hline & & 5019 & 5080 & $5019+5080$ & & \\
\hline Bradyrhizobium & $25,8 \mathrm{a}$ & $6,9 \mathrm{bc}$ & $6,4 \mathrm{abc}$ & $13,3 b c$ & $3562 a$ & $214,4 a$ \\
\hline $\operatorname{Bradyrhizobium}(\mathrm{T})^{2}$ & $23,7 \mathrm{a}$ & $14,9 \mathrm{abc}$ & $7,6 \mathrm{ab}$ & $22,5 \mathrm{ab}$ & $3796 a$ & $242,6 a$ \\
\hline Brady + Bacillus $^{3}$ & $25,0 \mathrm{a}$ & $22,6 a$ & $8,1 \mathrm{a}$ & $30,7 \mathrm{a}$ & $3554 a$ & $207,6 \mathrm{a}$ \\
\hline Brady. $(\mathrm{T})+$ Bacillus & $27,0 \mathrm{a}$ & 7,9abc & $10,8 \mathrm{a}$ & $18,7 \mathrm{abc}$ & $3766 a$ & $231,6 \mathrm{a}$ \\
\hline Brady.+metabólitos ${ }^{4}$ & $21,9 \mathrm{a}$ & $11,7 \mathrm{abc}$ & $3,6 a b c$ & $15,3 \mathrm{abc}$ & $3758 \mathrm{a}$ & $227,4 a$ \\
\hline Brady. (T)+metabólitos & $24,8 \mathrm{a}$ & $6,6 \mathrm{abc}$ & $4,3 \mathrm{abc}$ & $10,9 \mathrm{bc}$ & $3845 a$ & $232,2 \mathrm{a}$ \\
\hline Brady.+formulação ${ }^{5}$ & $26,7 \mathrm{a}$ & $23,3 \mathrm{a}$ & $8,7 \mathrm{a}$ & $32,0 \mathrm{a}$ & $3890 \mathrm{a}$ & $230,1 \mathrm{a}$ \\
\hline Brady.+ext. alcoólico ${ }^{6}$ & $23,0 \mathrm{a}$ & $17,0 \mathrm{ab}$ & $1,3 \mathrm{c}$ & $18,3 \mathrm{abc}$ & $3911 \mathrm{a}$ & $238,2 \mathrm{a}$ \\
\hline Não-inoculado & $22,0 \mathrm{a}$ & $5,5 \mathrm{c}$ & $1,6 \mathrm{bc}$ & $7,2 \mathrm{c}$ & $3626 a$ & $235,3 \mathrm{a}$ \\
\hline $\mathrm{CV}(\%)$ & 16,7 & 29,5 & 26,5 & 27,4 & 8,0 & 6,0 \\
\hline
\end{tabular}

${ }_{1}^{1}$ Médias seguidas de mesma letra não diferem, estatisticamente, pelo teste de Tukey $(\mathrm{P}<0,05)$.

2 Bradyrhizobium tolerante (T) aos metabólitos de Bacillus.

3 Bradyrhizobium adicionado na concentração de 5,0.10 células semente $^{-1}$ e Bacillus na concentração de $1,0.10^{6}$ células semente ${ }^{-1}$.

${ }^{4}$ Metabólitos adicionados na concentração de $40 \mathrm{~mL}$ de metabólitos $500 \mathrm{~g}^{-1}$ de sementes.

5 Metabólitos do Bacillus extraídos segundo McKeen et al. (1986), formulados como pó-molhável ( $5 \%$ dos metabólitos), misturados às sementes na proporção de $0,15 \mathrm{~g}$ do princípio ativo para $500 \mathrm{~g}$ de sementes.

${ }^{6}$ Extrato alcoólico contendo 0,5\% de metabólitos purificados do Bacillus, obtidos segundo McKeen et al. (1986), misturado às sementes na proporção de $0,1 \mathrm{~g}$ do extrato para $500 \mathrm{~g}$ de sementes.

formulação $(264 \mathrm{~kg})$ ou de bradirrizóbio $(\mathrm{T})+$ metabólitos (219 kg) (Tabela 6).

Em relação ao rendimento de trigo utilizado na sucessão da soja após os três experimentos, não foi constatado efeito residual, estatisticamente significativo, de nenhum dos tratamentos. Deve-se salientar, porém, que, em Londrina, nas parcelas onde a soja havia recebido inóculo de Bradyrhizobium e Bacillus, os rendimentos do trigo plantado sobre essas mesmas parcelas foram superiores (2.040 kg ha-1, em 1994 e $2.054 \mathrm{~kg} \mathrm{ha}^{-1}$, em 1995) ao trigo plantado nas parcelas que haviam sido infectadas exclusivamente com Bradyrhizobium (respectivamente $1.891 \mathrm{e} 1.797 \mathrm{~kg} \mathrm{ha}^{-1}$ ).

A co-inoculação de rizóbio com outras bactérias, como Bacillus, Azospirillum e Agrobacterium pode influenciar a simbiose com as leguminosas de várias maneiras, sendo destacadas a influência no aumen- to de competitividade do rizóbio inoculado (Triplett, 1990), o aumento da nodulação (Li \& Alexander, 1988) e redução de doenças nas raízes (Turner \& Backman, 1991). O potencial antagônico de B. subtilis a fungos fitopatogênicos de diversas culturas também é bastante conhecido, encontrando-se variabilidade, entre estirpes de Bacillus, em relação à ação fitopatogênica (Dunleavy,1955; Pusey \& Wilson, 1984; Bettiol \& Kimati, 1990; Turner \& Backman, 1991; Halverson et al., 1993; Krebs et al., 1993; Luz, 1994). Assim, a co-inoculação de rizóbio com Bacillus pode diminuir o ataque de patógenos de raízes e incrementar a nodulação, desde que os metabólitos do Bacillus não sejam tóxicos ao rizóbio. De fato, em uma etapa anterior deste trabalho, foram identificadas algumas estirpes de B. subtilis capazes de inibir, in vitro, os principais fungos patogênicos das sementes de soja (Araújo et al., 1995). Os metabólitos des- 
sas estirpes incrementaram, também, a taxa de emergência das sementes, resultando em uma porcentagem de germinação equivalente à da aplicação de um fungicida à base de Thiabendazol, na dose de

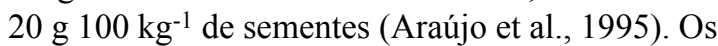
efeitos benéficos da co-inoculação de rizóbio com Bacillus podem resultar, ainda, da síntese de fitormônios, como ácido indolacético e ácido abscísico (Araújo, 1995), que estimulariam o crescimento radicular, aumentando os sítios para a nodulação.

Inicialmente, neste trabalho, verificou-se que, de um modo geral, todos os tratamentos com Bradyrhizobium aumentaram a nodulação, a ocupação dos nódulos e o rendimento em relação ao tratamento não-infectado. Esses dados confirmam, portanto, resultados de experimentos recentes, que evidenciaram os benefícios da reinoculação (Hungria et al., 1994, 1997; Nishi \& Hungria, 1996). Pouco se conhece, porém, sobre o comportamento da co-inoculação de Bradyrhizobium japonicum/ B. elkanii e Bacillus no campo, particularmente em solos com população estabelecida dessas espécies de bactérias. Neste estudo, a co-inoculação de Bradyrhizobium tolerante com células lavadas de B. subtilis resultou em incrementos, em relação à reinoculação apenas de Bradyrhizobium, na porcentagem de ocupação dos nódulos, na safra 93/94, de 88\% (Londrina) e 14\% (Ponta Grossa) e, em 94/95, em Londrina, um incremento de $131 \%$ foi constatado com o Bradyrhizobium não-tolerante. A adição de metabólitos aumentou significativamente a nodulação e, principalmente, a ocupação dos nódulos em Ponta Grossa (V3) (93/94), resultando em um incremento de $200 \%$ nesse parâmetro, em relação ao tratamento não-infectado. A complementação com formulados aumentou o número e a massa nodular, em Londrina e Ponta Grossa (93/94) e a porcentagem de ocupação dos nódulos, nos três ensaios. A resposta a diversos tratamentos co-infectados, em termos de número e massa nodular, constatada na safra 93/94, e não-detectada na safra seguinte pode resultar do fato de que, no primeiro ano de experimentação, houve um período prolongado de seca na semeadura, o que sugere que a co-inoculação pode favorecer a nodulação sob condições de estresse, conforme sugerido por Turner \& Backman (1991). Isso pode estar relacionado à produção de fitormônios por Bacillus, estimulando o crescimento das raízes e aumentando a capacidade de captação de água pela planta. Mecanismo semelhante foi comprovado em diversos ensaios de inoculação de gramíneas com bactérias do gênero Azospirillum (Hartmann \& Zimmer, 1994).

Na safra 93/94, em Londrina e Ponta Grossa, o maior rendimento de grãos foi obtido pela coinoculação de Bradyrhizobium + formulados, resultando em ganhos estatisticamente significativos, em relação ao tratamento não-infectado e expressivos mas não-significativos, em relação à inoculação de Bradyrhizobium. A co-inoculação da variante com metabólitos também incrementou, significativamente, o rendimento em Londrina, em relação ao controle não-infectado. Esses resultados confirmam os efeitos benéficos, na nodulação e no rendimento, obtidos pela co-inoculação de Bradyrhizobium com Bacillus em soja, relatados por outros autores (Li \& Alexander, 1988; Halverson \& Handelsman, 1991).

Em relação à melhor concentração de células de Bacillus para a co-inoculação, foi observado que a concentração de $1.10^{6}$ células lavadas semente ${ }^{-1}$, que proporcionou uma população em torno de $3,0.10^{5}$ células na rizosfera, pode não ter sido suficiente para proporcionar o maior estímulo à nodulação. Provavelmente isso pode ser atribuído a uma população insuficiente de Bacillus ou à ausência de maiores concentrações de metabólitos, produzidos pelo Bacillus, na fase inicial da cultura. A elevação da concentração do inóculo com Bacillus, via semente, porém, seria problemática, devido à necessidade da inoculação, também, do rizóbio em concentrações de cerca de $1,0.10^{5}$ células semente ${ }^{-1}$, podendo ocorrer perda de adesão das células à superfície das sementes. Essa limitação, porém, poderia ser eliminada pelo uso de metabólitos ou formulados de Bacillus. A recomendação de metabólitos ou formulados poderá, ainda, diminuir o emprego de fungicidas para sementes de soja, que hoje é generalizado (Embrapa, 1996) e cujos efeitos sobre as estirpes de bradirrizóbio podem ser bastante drásticos (Cattelan et al., 1995), prejudicando a nodulação. Por outro lado, o emprego de Bacillus, ou seus metabólitos, poderá contribuir, ainda, com fitormônios e sinais moleculares, 
incrementando o crescimento das raízes, a nodulação e as taxas de fixação do $\mathrm{N}_{2}$ e reduzindo a suscetibilidade a estresses hídricos.

\section{CONCLUSÃO}

A co-inoculação, em sementes de soja, de estirpes de Bradyrhizobium japonicum/Bradyrhizobium elkanii e de células de Bacillus subtilis ou seus metabólitos brutos ou formulados, proporciona incrementos na nodulação, na ocupação dos nódulos pelas estirpes de Bradyrhizobium e no rendimento da soja.

\section{AGRADECIMENTOS}

1. À Lígia M. de O. Chueire, Rinaldo B. Conceição, Leny M. Miura, José Z. Moraes e Rubson N. O. Sibaldelle, pelo auxílio durante a condução dos experimentos.

\section{REFERÊNCIAS}

ANDRADE, D.S.; HAMAKAWA, P.J. Estimativa do número de células viáveis de rizóbio no solo e em inoculantes por infecção em plantas. In: HUNGRIA, M.; ARAUJO, R.S. (Eds.). Manual de métodos empregados em estudos de microbiologia agrícola. Brasília: Embrapa-SPI, 1994. p.63-94.

ANDREEVA, I.N.; MANDKHAN, K.; RED'KINA, T.V.; MISHUSTIN, E.N.; IZMAILOV, S.F. Effect of Azospirillum brasilense on formation and nitrogenfixing activity of bean and soybean nodules. Soviet Plant Physiology, New York, v.38, p.897-904, 1991.

ARAÚJO, F.F. Efeito de Bacillus e seus metabólitos na competitividade e nodulação da soja (Glycine max [L.] Merrill) por Bradyrhizobium. Londrina: Universidade Estadual de Londrina, 1995. 117p. Tese de Mestrado.

ARAÚJO, F.F.; HENNING, A.; HUNGRIA, M.; LIMA, J. de. Caracterização do potencial antifúngico de Bacillus spp. isolados de solos do Paraná. In: HUNGRIA, M.; BALOTA, E.L.; COLOZZIFILHO, A.; ANDRADE, D.S. (Eds.). Microbiologia do solo: desafios para o século XXI. Londrina: Iapar/ Embrapa-CNPSo, 1995. p.450-455.
BETTIOL, W.; KIMATI, H. Efeito de Bacillus subtilis sobre Pyricularia oryzae agente causal de brusone do arroz. Pesquisa Agropecuária Brasileira, Brasília, v.25, n.8, p.1165-1174, 1990.

BOTTOMLEY, P.J. Ecology of Bradyrhizobium and Rhizobium. In: STACEY, G.; BURRIS, R.H.; EVANS, H.J. (Eds.). Biological nitrogen fixation. New York: Chapman and Hall, 1992. p.293-348.

BUCHANAN, R.E.; GIBBONS, N.G. Bergey's manual of determinative bacteriology. Baltimore: The Willians \& Wilkens, 1975. 1268p.

CAETANO-ANOLLÉS, G.; BAUER, W.D. Enhanced nodule initiation on alfafa by wild-type Rhizobium meliloti co-inoculated with nod gene mutants and other bacteria. Planta, Berlin, v.174, p.385-395, 1988.

CATTELAN, A.J.; SPOLADORI, C.L.; HENNING, A.A. Efeito do tratamento de sementes de soja com fungicidas recomendados sobre a fixação do nitrogênio atmosférico e a sobrevivência do Bradyrhizobium japonicum em casa de vegetação. In: HUNGRIA, M.; BALOTA, E.L.; COLOZZI-FILHO, A.; ANDRADE, D.S. (Eds.). Microbiologia do solo: desafios para o século XXI. Londrina: Iapar/EmbrapaCNPSo, 1995. p.398-402.

DUNLEAVY, J. Control of damping-off sugar beet by Bacillus subtilis. Phytopathology, Saint Paul, v.45, p.252-258, 1955.

EMBRAPA. Centro Nacional de Pesquisa de Soja (Londrina, PR). Recomendações técnicas para a cultura da soja no Paraná, 1996/97. Londrina: EmbrapaSoja, 1996. 187p. (Embrapa-Soja. Documentos, 97).

FEIJE, F.; ANGER, V. Spot tests in inorganic analyses. Analytical Chemistry Acta, Netherlands, v.149, p.363-367, 1972.

FRED, E.B.; BALDWIN, I.L.; McCOY, E. Root nodule bacteria of leguminous plants. Madison: The University of Wisconsin Press, 1932. 343p.

HALVERSON, L.J.; CLAYTON, M.K.; HANDELSMAN, J. Population biology of Bacillus cereus UW85 in the rhizosphere of field-grown soybean. Soil Biology \& Biochemistry, Oxford, v.25, p.485-493, 1993.

HALVERSON, L.J.; HANDELSMAN, J. Enhancement of soybean nodulation by Bacillus cereus UW85 in the field and in a growth chamber. Applied and Environmental Microbiology, Washington, v.57, p.2767-2770, 1991. 
HARTMANN, A.; ZIMMER, W. Physiology of Azospirillum. In: OKON, Y. (Ed.). Azospirillum/ plant associations. Boca Raton: CRC Press, 1994. p.15-39.

HUNGRIA, M.; VARGAS, M.A.T.; CAMPO, R.J. A inoculação da soja. Londrina: Embrapa-CNPSo, 1997. 20p. (Embrapa-CNPSo. Circular técnica, 17).

HUNGRIA, M.; VARGAS, M.A.T.; SUHET, A.R.; PERES, J.R.R. Fixação biológica do nitrogênio na soja. In: ARAÚJO, R.S.; HUNGRIA, M. (Eds.). Microrganismos de importância agrícola. Brasília: Embrapa-SPI, 1994. p.9-89.

JORDAN, D.C. Transfer of Rhizobium japonicum Buchanan 1980 to Bradyrhizobium gen. nov., a genus of slow growing root-nodule bacteria from leguminous plants. International Journal of Systematic Bacteriological, Washington, v.32, p.136-139, 1982.

KREBS, B.; JUNGE, H.; OCKHARDT, A.; HODING, B.; HEUBNER, D.; ERBEN, U. Bacillus subtilis: an effective biocontrol agent. Pesticide Science, Barking, v.37, p.427-429, 1993.

KUYKENDALL, L.D.; SAXENA, B.; DEVINE, T.E.; UDELL, S.E. Genetic diversity in Bradyrhizobium japonicum, Jordan, 1982 and a proposal for Bradyrhizobium elkanii sp. nov. Canadian Journal of Microbiology, Ottawa, v.38, p.501-505, 1992.

LI, D.; ALEXANDER, M. Co-inoculation with antibioticproducing bacteria to increase colonization and nodulation by rhizobia. Plant and Soil, Dordrecht, v.108, p.211-219, 1988.

LUZ, W.C. Efeito da microbiolização de sementes no rendimento e controle da podridão comum nas raízes e de patógenos das sementes de trigo. Fitopatologia Brasileira, Brasília, v.19, p.144-148, 1994.

McKEEN, C.D.; REILLY, C.C.; PUSEY, P.L. Production and partial characterization of antifungal substances antagonistic to Monilinia fructicola from Bacillus subtilis. Phytopathology, Saint Paul, v.76, p.136139, 1986.

MYTTON, L.R.; SKØT, L. Breeding for improved symbiotic nitrogen fixation. In: HAYWARD, M.D.;
BOSEMARK, N.O.; ROMAGOSA, I. (Eds.). Plant breeding: principles and prospects. London: Chapman \& Hall, 1993. p.451-472.

NISHI, C.Y.M.; HUNGRIA, M. Efeito da reinoculação da soja [Glycine $\max ($ L.) Merrill] em um solo com população estabelecida de Bradyrhizobium com as estirpes SEMIA 566, 586, 587, 5019, 5079 e 5080. Pesquisa Agropecuária Brasileira, Brasília, v.31, n.5, p.359-368, 1996.

OMAR, S.A.; ABD-ALLA, M.H. Enhancement of faba bean nodulation, nitrogen fixation and growth by different microorganisms. Biologia Plantarum, Prague, v.36, p.295-300, 1994.

PLAZINSKI, J.; ROLFE, B.G. Analysis of the pectolytic activity of Rhizobium and Azospirillum strains isolated from Trifolium repens. Journal of Plant Physiology, Stuttgart, v.120, p.181-187, 1985.

PUSEY, P.L.; WILSON, C.L. Postharvest biological control of stone fruit brown rot by Bacillus subtilis. Plant Disease, Saint Paul, v.68, p.753-756, 1984.

SINGH, C.S.; RAO, N.S.S. Associative effect of Azospirillum brasilense with Rhizobium japonicum on nodulation and yield of soybean (Glycine max). Plant and Soil, Dordrecht, v.53, p.387-392, 1979.

SOMASEGARAN, P.; HOBEN, H.J. Handbook of rhizobia: methods in legume-Rhizobium technology. New York: Springer-Verlag, 1994. 450p.

STREETER, J.G. Failure of inoculant rhizobia to overcome the dominance of indigenous strains for nodule formation. Canadian Journal of Microbiology, Ottawa, v.40, p.513-522, 1994.

TRIPLETT, E.W. The molecular genetics of nodulation competitiveness in Rhizobium and Bradyrhizobium. Molecular Plant-Microbe Interaction, Saint Paul, v.3, p.199-206, 1990.

TURNER, J.T.; BACKMAN, P.A. Factors relating to peanut yield increases after seed treatment with Bacillus subtilis. Plant Disease, Saint Paul, v.75, p.347-352, 1991. 